\title{
Study on the Reconfiguration of Dual Resource Cellular Manufacturing System
}

\author{
Jiajing Fan*, Min Cao, Ling Zhang and Siding Jiang \\ School of Economics and Management, Zhejiang University of Science and Technology, Hangzhou, 310023, China
}

\begin{abstract}
With the change of market environment, manufacturing system must respond to changes of the outside world with the fastest speed. After detailed analysis of the impact of human resource on cellular manufacturing system, this paper purposes an equipment reconfiguration model to achieve minimum number of equipment reconfiguration times and material handling time, and builds a human resource work task reschedule model to achieve the maximum of total operation skill level and similarity of equipment operation content at two neighboring periods and minimum of uneven distribution of workers' technical level. At the end, we put forward a numerical example to specifically illustrate reconfiguration models.
\end{abstract}

Keywords: Cellular manufacturing system, Equipment resource, Human resource, Mathematical model, Reconfiguration, Technical level.

\section{INTRODUCTION}

Along with the advancement of science and technology, the product supply market has become more international thus making the consumption more personalized and diversified. Customer mass production mode emerges as the time required driven by customer order and characterized by small batch, many varieties, multi-functional, fast delivery and shorter product markets. Manufacturing enterprises need to change production from product-oriented to customeroriented, from seller's market to buyer's market. Obviously, the traditional manufacturing system such as rigid manufacturing system cannot meet this requirement, so Koren [1] proposed a new generation of manufacturing system Reconfigurable Manufacturing System (RMS). RMS is a variable manufacturing system that rapidly responds to market demand change. It dynamically changes its configuration by changing the system component, increasing and decreasing the component number and changing the relationship between the components based on the prescribed scope of system planning and design. It can shorten system development and ramp time, achieve low reconfiguration cost, higher machining quality and economic benefit. Manufacturing system reconfiguration is based on Cellular Manufacturing (CM). $\mathrm{CM}$ is originally derived from the Group Technology. CM can combine flexibility of work-shop and high efficiency of flow line production and it can also produce varieties of and less batch production with approximate cost of rigid manufacturing system. CM can meet various challenges including time, quality, flexibility and cost and it represents the new production mode. And then reconfigurable cellular manufacturing system becomes the most preferable of enterprise. Reconfigurable manufacturing system is a complicated

*Address correspondence to this author at the School of Economics and Management, Zhejiang University of Science and Technology, Hangzhou, 310023, China; 310023; Tel: 13758242715; E-mail: carole_cn@163.com system, in addition to the equipment and machinery; human resource also plays an important role in making the system flexible to carry out high-efficient operation. More than $80 \%$ of the manufacturing enterprises in our country are small and medium enterprises and labor-intensive industries. Although, in recent years, enterprises speed up the application steps of numerical control and machining center, the mechanical processing numerical control rate is still hovering at $30 \%$. The ordinary machine tools still occupy the mainstream position because of its low prices. The fusion of human being and equipment technology problem is particularly prominent. So, reconfigurable cellular manufacturing system must consider equipment resource and human resource at the same time and can promote its effective operation by reasonable reconfiguration of dual resources.

This paper provides a detailed analysis of the impact of human resource on cellular manufacturing system, and then introduced the equipment reconfiguration model and human resource task rearrangement model to provide the theoretical basis of cellular manufacturing system reconfiguration.

\section{LITERATURE REVIEW}

Nowadays, the research content on reconfigurable cellular manufacturing system is mainly about multi-skilled workers' task allocation. Askin and Huang [2] put forward two-integers programming model for workers' task allocation and training. The first one decides task allocation and training needed by each cell, and the other one decides an individual's training program. Bokhorst [3] considered workers' task allocation for a long period to meet the demand fluctuation and absence of workers. A mixed integer programming model was put forward by Norman to arrange workers in manufacturing cell to gain the biggest profit [4]. Jannes [5] proposed a mathematical model considering workers task allocation for virtual manufacturing. The goal of this model is to achieve maximum output and minimum number of additional machines and workers. Solimanpur [6] 
put forward a fuzzy goal programming model to solve multiskilled workers task allocation and production plan in virtual cellular manufacturing system. Mahdavi [7] proposed a new model for reconfigurable manufacturing system considering multi-periodic production plans, dynamic system reconfiguration, equipment capacity, available time as well as workers task allocation and other factors. Fan [8] considered equipment cell formation and human resource task allocation as well as cell layout in the manufacturing system.

Cell productivity not only depends on technology and management, but also on effective interaction between team members. Askin [9] proposed a mixed integer programming model to determine workers task allocation and training process to build a highly coordinated working team. The author established a working team according to conation and the ability and skills of each cell based family. Conation and skills are measured by Kolbe Conative Index (KCI) [10], including individual enlightenment, adaptation and resistance. Erin [11] also used KCI to analyze the conation and instinct of workers to establish a work team. Now, researchers have introduced the problem of team performance in determining the cellular manufacturing efficiency and used conation and instinct of KCI as a foundation for cell reconfiguration. However, the data of enlightenment, adaptation and resistance need a lot of investigation and statistical analysis to obtain a more accurate result. And with the unceasing change of environment and labor team instability, it becomes more difficult and costly to gain the basic data. Therefore, a more reasonable method is required to carry out quantitative analysis of the effect of team work on cellular manufacturing system performance.

To solve the problem mentioned above, this paper analyzes the impact of human resource task reallocation on the cellular manufacturing system reconfiguration and then builds a mathematical model to confirm the reconfiguration scheme of equipment resource and human resource.

\section{THE EFFECT OF TASK REALLOCATION ON MANUFACTURING SYSTEM}

Human resource plays an important role in manufacturing system, and readjustment of the workers' task is bound to affect the overall efficiency including time efficiency, quality and team efficiency. Therefore, it is crucial to clear the influence factors of system efficiency in order to ensure that workers can carry out their work with the highest efficiency.

\subsection{The Analysis of Factors determining Time Efficiency}

In the process of manufacturing cell reconfiguration, the task contents of each worker have to be rearranged. Each multiskilled worker can carry out different tasks, but considering work continuity, each work has to be completed in a certain amount of time to opt the new work to reach the highest work level. So it is important to consider the similarity in task content of one worker operating in two neighboring periods during task reallocation. The task content similarity of one worker operating in two neighboring periods is greater, the time needs to adapt a new work is shorter, and thus, the efficiency becomes relatively higher.
At the same time, it is clear that the skill level of the worker also affects the system's efficiency. The higher skill level of worker operating one machine implies that the operation proficiency and efficiency are higher.

So in the process of workers' task reallocation, we must consider the task content similarity of one worker operating in two neighboring periods and skill level of the new task of worker operating to achieve the highest efficiency.

\subsection{The Analysis of Factors of Quality Efficiency}

Product quality determines the life of enterprises. During workers' task reallocation, the product quality will be affected and the qualified rate will become volatile. According to the theory of learning, the skill level of workers' mastering is higher, and the product quality qualified rate will be relatively higher. So we hope to gain the highest skill level for a new task of each worker to guarantee high product quality.

\subsection{The Analysis of Factors of Team Efficiency}

In previous studies, some researchers introduced team performance in the manufacturing cell and carried out a quantitative analysis on manufacturing cell formation problem. For example, Askin [9] built three essence models for enlightenment, adaptation and resistance to obtain high efficiency. However, the data of enlightenment, adaptation and resistance need a lot of investigations and statistical analysis to obtain a more accurate result. And with the unceasing change of environment and labor team instability, it becomes more difficult and costly to gain the basic data. Molleman [12] came to the conclusion, that even distribution of workers in the same cell or system will lead to the lowest production cycle and production time in all operational conditions. So this paper used this conclusion to analyze the overall performance of working team.

According to the analysis mentioned above, the skill level of work operating machines affects the time efficiency and product quality, the task content similarity of one worker operating in two neighboring periods affects the time efficiency and skill level distribution of team members affects the whole team work efficiency. So workers skill level, task content similarity of one worker operating in two neighboring periods and skill level distribution of team members will be the human goal in manufacturing cell reconfiguration.

\section{DUAL RESOURCE RECONFIGURATION MODEL}

This paper builds dual resource cellular manufacturing system model based on the analysis mentioned above.

The model includes two parts, the first is equipment cell reconfiguration and the other is workers' task reallocation based on the equipment cell reconfiguration scheme.

\subsection{Machies' Reconfiguraiton Model}

This section builds a machine reconfiguration model aimed at obtaining minimum reconfigurations and material handling time. 
Considering the complexity of machine reconfiguration problem, it is based on the following real conditions. Each product has many operation routes and each route is known, but each product can only choose one route to carry out operation. The demand of each product is known. The number of each machine type and the available production time of each machine are known. The number of cell is known and each cell is limited by the size. Machines' failures are not considered.

\subsubsection{Parameters and Variables}

\section{(1) Parameters}

i denotes the part , $i=1,2, \ldots, P$, where $P$ denotes the type number of the part;

$\mathrm{j}, \mathrm{j}$ ' denote the machine, $\mathrm{j}, \mathrm{j}{ }^{\prime}=1,2, \ldots, \mathrm{M}$, where $\mathrm{M}$ denotes the type number of the machine;

$n_{j}$ denotes the total number of machine type $j$;

$d_{j}$ denotes machine $d$ of machine type $j$;

$r$ denotes the route, $r=1,2, \ldots, R_{i}$, where $R_{i}$ denotes the number of possible routes for product $\mathrm{i}$;

$\mathrm{k}$ denotes the cell, $\mathrm{k}=1,2, \ldots, \mathrm{K}$, where $\mathrm{K}$ denotes the number of cells;

$\mathrm{W}_{\mathrm{ijr}}$ is equal to 1 when the product $\mathrm{i}$ needs machine type $\mathrm{j}$ in route $r$, otherwise it is equal to 0 ;

$t_{i r j}$ denotes the operation time of product $i$ on machine type $j$ in route $r$;

$\mathrm{W}_{\mathrm{j}}$ denotes the capability of the machine type $\mathrm{j}$;

$D_{i}$ denotes the demand of product $i$;

$\mathrm{U}$ denotes the largest number of machines for each cell;

$\mathrm{L}$ denotes the smallest number of machines for each cell;

$\mathrm{B}$ denotes an infinite number.

(2) Initial conditions

$\mathrm{x}_{\mathrm{jdjk} 1}$ equals 1 when machine $\mathrm{d}$ of machine type $\mathrm{j}$ is arranged in the cell $\mathrm{k}$, and the location is

in rowa1and columnb1; otherwise it equals 0 ;

(3) Variables

$\mathrm{x}_{\mathrm{irk}}$ equals 1 when product $\mathrm{i}$ is arranged in cell $\mathrm{k}$ using route $\mathrm{r}$ during this period, and otherwise it equals 0 ;

$\mathrm{x}_{\mathrm{jdjk}}$ equals 1 when machine $\mathrm{d}$ of machine type $\mathrm{j}$ is assigned to cell $\mathrm{k}$ during this period, and otherwise it equals 0 ;

$\mathrm{x}_{\mathrm{ijdj}}$ equals 1 when operation op in route $\mathrm{r}$ of product $\mathrm{i}$ using route $r$ needs machine $d$ of machine type $j$, and otherwise it equals 0 .

\subsubsection{Mathematical Model}

(1) Objective function

$\min Z_{1}=C_{1}$

$\min Z_{2}=C_{2}$

Where:

$$
\begin{aligned}
& C_{1}=\sum_{i=1}^{P} \sum_{j=1}^{M} \sum_{d j=1}^{n_{j}} \sum_{r=1}^{R_{i}} W_{i j r} \sum_{k=1}^{K}\left|x_{j d j k} \times x_{i j d j}-x_{i r k}\right| / 2 \\
& C_{2}=\sum_{k=1}^{K} \sum_{j=1}^{M} \sum_{d j=1}^{n_{j}}\left|x_{j d j k}-x_{j d j k 1}\right| / 2
\end{aligned}
$$

(2) Constrains

$\sum_{k=1}^{K} \sum_{r=1}^{R_{i}} x_{i r k}=1 \forall i$

$\sum_{k=1}^{K} x_{j d j k}=1 \quad \forall j, d_{j}$

$\sum_{j=1}^{M} \sum_{d j=1}^{n_{j}} x_{j d j k} \geq L \forall k$

$\sum_{j=1}^{M} \sum_{d j=1}^{n_{j}} x_{j d j k} \leq U \forall k$

$\sum_{d j=1}^{n j} x_{i j d j}=x_{i r k} \times W_{i j r} \quad \forall i, j, r, k$

$\sum_{i=1}^{P} \sum_{r=1}^{R i} \sum_{k=1}^{K} x_{i r k} \times t_{i j} \times x_{i j d j} \leq W_{j} \quad \forall j, d_{j}$

$x_{i r k}, x_{j d i k}, x_{i j d j}=0 o r 1, \forall i, r, k, j, d_{j}$

The objective function includes two parts. The first part stands for the minimum times for material handling between different cells, given in Equation (1) and Equation (3). The second part stands for the minimum reconfiguration times, given in Equation (2) and Equation (4).

In the constraints, Equation (5) represents that each product can only select one route to operate; Equation (6) represents that each machine can only be located in one cell; Equation (7) and Equation (8) are used to ensure cell size limitation; Equation (9) represents that each operation of each product can be operated only in one machines; Equation (10) ensures machine capabilities; Equation (11) represents that each variable equals one or zero.

\subsection{Work Task Reallocation}

Based on the equipment reconfiguration project and considering technology of multi-skilled worker, a workers' task reallocation model is built to gain the highest total skill level of workers operating the machines in this period, the highest task content similarity of one worker operating in two neighboring periods and the most uniform distribution of skill level of team members in each cell.

Considering the complexity of machines reconfiguration problem, it is based on the following real conditions. The content similarity of two different tasks is known. Workers' skill level is known. Operation quality is determined by the operation skill level. 


\subsubsection{Parameters and Variables}

(1) Parameters

$\mathrm{h}$ denotes the worker, $\mathrm{h}=1,2, \ldots \mathrm{H}$, where $\mathrm{H}$ denotes the number of workers;

$\mathrm{S}_{\mathrm{jj}}$ ' denotes the similarity of machine type $\mathrm{j}$ and $\mathrm{j}$ ' ;

$y_{h j}$ denotes the skill level of worker $h$ operating machine type $\mathrm{j}$;

$\mathrm{yy}_{\mathrm{hj}}$ is equal to 1 when the skill level is equal or greater than 1 of worker $h$ operating machine type $j$

$\mathrm{G}$ denotes the maximum number of machines that one worker can operate;

$A j=\left\{\begin{array}{rr}1 & \text { machine type } \mathrm{j} \text { can be operated by one worker with other machines } \\ G & \text { machine type } \mathrm{j} \text { cannot be operated by one workerwith other machines } ;\end{array}\right.$

$\mathrm{HM}_{\mathrm{h}}$ denotes the set of worker h operating machine type;

(2) Initial conditions

$\mathrm{x}_{\mathrm{hjdj} 1}$ equals 1 when machine $\mathrm{d}$ of machine type $\mathrm{j}$ is operated by worker $\mathrm{h}$ in the last period, and otherwise it equals 0

$\mathrm{x}_{\mathrm{hj} 1}$ equals 1 when worker $\mathrm{h}$ operated machine type $\mathrm{j}$ in the last period, and otherwise it equals 0 ;

$\mathrm{HM} 1_{\mathrm{h}}$ denotes the set of worker $\mathrm{h}$ operating machine type in the last period.

\section{(3) Variable}

$\mathrm{X}_{\mathrm{hjdj}}$ equals 1 when machine $\mathrm{d}$ of machine type $\mathrm{j}$ is operated by worker $h$ in this period, and otherwise it equals 0 ;

$\mathrm{x}_{\mathrm{hj}}$ equals 1 when worker $\mathrm{h}$ operated machine type $\mathrm{j}$ in this period, and otherwise it equals 0 ;

$\mathrm{x}_{\mathrm{hk}}$ equals 1 when worker $\mathrm{h}$ is arranged in cell $\mathrm{k}$.

\subsubsection{Mathematical Model}

(1) Objective function

$\max Z_{3}=C_{3}$

$\max Z_{4}=C_{4}$

$\min Z_{5}=C_{5}$

Where:

$C_{3}=\sum_{j=1}^{M} \sum_{h=1}^{H} y_{h j} \times x_{h j}$

$C_{4}=\sum_{h=1}^{H} \sum_{j \in H M 1_{h}} \sum_{\substack{j^{\prime} \in H M h \\ j^{\prime} \notin H M 1 h}} S_{j j^{\prime}} \times x_{h j 1} \times x_{h j}$

$C_{5}=\sum_{k=1}^{K} \sum_{h=1}^{H}|(S H(k, h)-\bar{H}(k))|$

$+\sum_{k=1}^{K} \sum_{h=1}^{H}|(S L H(k, h)-\overline{L H}(k))|$
Where

$\bar{H}(k)=\frac{\sum_{h=1}^{H} S H(k, h)}{\sum_{h=1}^{H} x_{h k}} \forall k$

$S H(k, h)=\sum_{j=1}^{M} \sum_{d j=1}^{n_{j}} y y_{h j} \times x_{h k} \times x_{j d j k} \quad \forall k, h$

$\mathrm{H}(\mathrm{k})$ stands for the average skill number of worker master in cell $\mathrm{k}$;

$\mathrm{SH}(\mathrm{k}, \mathrm{h})$ stands for the skill number of worker master of worker $\mathrm{h}$ in cell $\mathrm{k}$;

$$
\begin{gathered}
\overline{L H}(k)=\frac{\sum_{h=1}^{H} \operatorname{SLH}(k, h)}{\sum_{h=1}^{H} x_{h k}} \forall k \\
\operatorname{SLH}(k, h)=x_{h k} \times \frac{\sum_{j=1}^{M} \sum_{d_{j=1}}^{n_{j}} y_{h j} \times x_{j d j k}}{\sum_{j=1}^{M} \sum_{d_{j}=1}^{n j} y y_{h j} \times x_{j d j k}} \forall k, h
\end{gathered}
$$

$\mathrm{LH}(\mathrm{k})$ stands for the average skill level of worker master in cell $\mathrm{k}$;

$\operatorname{SLH}(\mathrm{k}, \mathrm{h})$ stands for the skill level of worker master of worker $\mathrm{h}$ in cell $\mathrm{k}$;

(2) Constraints

$\sum_{h=1}^{H} x_{h j d_{j}}=1 \quad \forall j, d_{j}$

$\sum_{j=1}^{M} \sum_{d j=1}^{n_{j}} A_{j} x_{h j d_{j}} \leq G \forall h$

$x_{h j d_{j}} \times x_{h k}=x_{j d j k} \quad \forall h, k, j, d_{j}$

$\sum_{k=1}^{K} x_{h k}=1 \quad \forall h$

$\sum_{d j=1}^{n_{j}} x_{h j d j} \leq B \times x_{h j} \quad \forall h, j, d_{j}$

$x_{h j d}, x_{h k}, x_{h j}=0$ or $1, \forall k, j, d_{j}, h$

The objective function includes three parts. The first part stands for the highest total skill level for all workers operating the machines in this period, given in Equation (12) and Equation (15). The second part stands for the highest task content similarity of two neighboring periods for all workers, given in Equation (13) and Equation (16). The third part stands for the minimum imbalance distribution of skill level of team members in each cell, given in Equation (14), Equation (17), Equation (18) and Equation (19). 
Table 1. The cell division and worker task arrangement in last period.

\begin{tabular}{|c|c|c|c|}
\hline & Cell 1 & Cell 2 & Cell 3 \\
\hline \hline \multirow{2}{*}{ Machines } & M1,M4,M5,M6 & M1,M2,M3,M5 & M4,M7,M8 \\
\hline \multirow{2}{*}{ Human } & H1:M1,M4 & H2:M1,M5 & H5:M4,M8 \\
\cline { 2 - 4 } & H3:M5,M6 & H4:M2,M3 & H6:M7 \\
\hline
\end{tabular}

Table 2. Products operation routes.

\begin{tabular}{|c|c|c|c|c|c|c|c|c|c|c|c|}
\hline & M1 & M2 & M3 & M4 & M5 & M6 & M7 & M8 & M9 & M10 & Batch \\
\hline P1-1 & - & - & 1 & - & 1 & 1 & 1 & - & - & - & 200 \\
\hline P1-2 & 1 & - & 1 & 1 & 1 & - & - & - & - & - & 200 \\
\hline P2 & 1 & - & - & 1 & - & - & - & 1 & - & 1 & 350 \\
\hline P3-1 & - & 1 & - & - & 1 & 1 & - & 1 & - & - & 150 \\
\hline P3-2 & 1 & 1 & - & - & 1 & 1 & - & - & - & - & 150 \\
\hline P4-1 & 1 & - & 1 & - & 1 & - & 1 & - & - & - & 280 \\
\hline P4-2 & - & 1 & - & 1 & 1 & - & - & - & - & 1 & 280 \\
\hline P5 & 1 & 1 & - & 1 & - & - & 1 & - & - & - & 160 \\
\hline P6-1 & - & - & 1 & 1 & - & - & - & 1 & 1 & - & 300 \\
\hline P6-2 & - & - & - & 1 & - & 1 & - & 1 & - & 1 & 300 \\
\hline P7-1 & 1 & 1 & - & 1 & - & - & 1 & - & - & - & 120 \\
\hline P7-2 & - & - & 1 & 1 & 1 & - & 1 & - & - & - & 120 \\
\hline P8 & 1 & - & - & - & 1 & 1 & - & - & - & 1 & 230 \\
\hline P9-1 & - & 1 & - & - & - & 1 & 1 & - & 1 & - & 200 \\
\hline P9-2 & - & - & - & 1 & - & 1 & 1 & - & 1 & - & 200 \\
\hline P10 & - & 1 & - & - & - & 1 & - & 1 & 1 & - & 150 \\
\hline
\end{tabular}

Note: P1-1 means the first operating route of P1 and P1-2 means the second operating route of P1.

In the constraints, Equation (20) ensures that each machine must be in operation by one worker. Equation (21) represents that each worker can operate only $G$ unit machines at most, and when one machine cannot be operated with others, then the worker can only operate this machine. Equation (22) ensures that machines operated by one worker must be arranged in the same cell. Equation (23) ensures that each worker can only be arranged to one cell. Equation (24) represents the relationship between variables and equation (25) represents variable ranges.

\section{NUMERICAL EXAMPLE ANALYSIS}

Assuming that there were eight types of machines (M1M8), where M1, M4 and M5 each had two units and others had only one unit in the last period. Six workers (H1-H6) operated these 11 units machines, the cellular manufacturing system arrangement can be seen in Table $\mathbf{1}$.
Along with the upgrading of products, the cellular manufacturing system cannot meet the production demand. For better production of ten products (P1-P10), two types of machines are required, M9 and M10. At the same time, P2, P5 P8 and P10 can only be dealt in accordance with only the one route to operate while others have two operation routes.

For operation of these machines, one worker H7 is added. And after skills training as well as man-machines operation analysis, now each worker can operate two or three unit machines, but if M10 is involved, the worker can no longer operate other machines. The products operation routes can be seen in Table 2.

According to Equation (1) to Equation (11), for ensuring the minimum material handling batch and machines reconfiguration, we can get the result as shown in Table 3.

At this time, the material handling batch is 1040 and the total machines reconfiguration time is 7. Now, M1, M3, M4, 
Table 3. Reconfiguration scheme.

\begin{tabular}{|c|c|c|c|c|c|c|c|c|c|c|c|c|c|}
\hline & M1 & M4 & M5 & M3 & M7 & M1 & M2 & M9 & M5 & M6 & M4 & M8 & M10 \\
\hline P1-2 & 1 & 1 & 1 & 1 & - & - & - & - & - & - & - & - & - \\
\hline P4-1 & 1 & - & 1 & 1 & 1 & - & - & - & - & - & - & - & - \\
\hline P5 & 1 & 1 & - & - & 1 & - & 1 & - & - & - & - & - & - \\
\hline P7-2 & - & - & 1 & 1 & 1 & - & - & - & - & - & - & - & - \\
\hline P3-2 & - & - & - & - & - & 1 & 1 & - & 1 & 1 & - & - & - \\
\hline P8 & - & - & - & - & - & 1 & - & 1 & 1 & - & - & - & 1 \\
\hline P9-1 & - & - & - & - & 1 & - & 1 & 1 & - & 1 & - & - & - \\
\hline P10 & - & - & - & - & - & - & 1 & 1 & - & 1 & - & 1 & - \\
\hline P2 & - & - & - & - & - & 1 & - & - & - & - & 1 & 1 & 1 \\
\hline P6-2 & - & - & - & - & - & - & - & - & - & 1 & 1 & 1 & 1 \\
\hline Worker & \multicolumn{3}{|c|}{ H1 } & \multicolumn{2}{|c|}{ H6 } & \multicolumn{3}{|c|}{$\mathrm{H} 2$} & \multicolumn{2}{|c|}{$\mathrm{H} 3$} & \multicolumn{3}{|c|}{ H5 } \\
\hline
\end{tabular}

Table 4. Skill level of each worker operation machines.

\begin{tabular}{|c|c|c|c|c|c|c|c|c|c|c|}
\hline & M1 & M2 & M3 & M4 & M5 & M6 & M7 & M8 & M9 & M10 \\
\hline H1 & 3 & - & 2 & 4 & 3 & 2 & - & - & 3 & - \\
\hline $\mathrm{H} 2$ & 4 & 2 & 1 & - & 3 & - & 3 & - & 3 & - \\
\hline H3 & - & 2 & 2 & - & 3 & 4 & - & 5 & - & 4 \\
\hline $\mathrm{H} 4$ & - & 2 & 3 & - & - & - & 2 & - & - & 4 \\
\hline H5 & 2 & - & - & 4 & - & 4 & - & 4 & - & 3 \\
\hline H6 & 2 & - & 3 & 3 & 2 & - & 3 & - & 2 & - \\
\hline
\end{tabular}

Note: 4 means the skill level of worker H2 operating in machine M1, and 2 means the skill level of worker H3 operating in machine M3. The blank means the worker cannot operate the machine.

M5 and M7 belong to the first cell; M1, M2, M5, M6 and M9 belong to the second cell; M4, M8 and M10 belong to the third cell; and the operation routes of products P1-P10 are 2-1-2-1-1-2-2-1-1-1 respectively.

Based on the machines cell division project, considering workers skill level (shown in Table 4) and task content similarity (shown in Table 5), using Equation (12) to Equation (25), we can obtain the worker task rearrangement scheme. At this period, H1 operates M1, M4 and M5 and H6 operates M3 and M7 in the first cell. H2 operates M1, M2 and M9 and $\mathrm{H} 3$ operates M5 and M6 in the second cell. H5 operates M4 and M8 and H4 operates M10 in the third cell. According to this scheme, the total operation skill level of all workers operating machines in this period is 44 , the workers task content similarity of neighboring period is 6.6 and the team member skill imbalance in all cells is 5 .

\section{CONCLUSION}

The introduction and implementation of a reconfigurable cellular manufacturing system is involved in not only a technological revolution but also an integration process of workforce resource management and advanced technology for any enterprises. The rapid fluctuation of product demands in modern society requires frequent machine reconfiguration and workforce-resource-team reorganization. So this paper proposed a cellular manufacturing reconfiguration process and method. And then based on the detailed analysis of human resource impaction on manufacturing cell efficiency, a mathematical model for machines reconfiguration and worker task arrangement is built to provide theoretical basis for cellular manufacturing reconfiguration. 
Table 5. The similarity of machines operation.

\begin{tabular}{|c|c|c|c|c|c|c|c|c|c|c|}
\hline & M1 & M2 & M3 & M4 & M5 & M6 & M7 & M8 & M9 & M10 \\
\hline \hline M1 & 1 & 0.7 & 0.65 & 0.9 & 0.8 & 0.7 & 0.75 & 0.2 & 0.8 & 0.3 \\
\hline M2 & - & 1 & 0.8 & 0.8 & 0.9 & 0.4 & 0.7 & 0.35 & 0.7 & 0.5 \\
\hline M3 & - & - & 1 & 0 & 0.15 & 0.6 & 0.75 & 0.8 & 0.75 & 0 \\
\hline M4 & - & - & - & 1 & 0.7 & 0.5 & 0.6 & 0.65 & 0.3 & 0.7 \\
\hline M5 & - & - & - & - & 1 & 0.9 & 0.8 & 0.75 & 0.85 & 0.3 \\
\hline M6 & - & - & - & - & - & 1 & 0.4 & 0 & 0.7 & 0.8 \\
\hline M7 & - & - & - & - & - & - & 1 & 0.3 & 0.3 & 0.3 \\
\hline M8 & - & - & - & - & - & - & - & 1 & 0 \\
\hline M9 & - & - & - & - & - & - & - & - & 1 \\
\hline M10 & - & - & - & - & - & - & - & - & 0 \\
\hline
\end{tabular}

\section{CONFLICT OF INTEREST}

The authors confirm that this article content has no conflict of interest.

\section{ACKNOWLEDGEMENTS}

The authors would like to acknowledge the Zhejiang Provincial Nature Science Fund (No. LQ13G010008) for their financial of this study.

\section{REFERENCES}

[1] Y. Koren, T. Moriwaki, G. Pritschow, F. Jovane, G. Ulsoy, and H.V Brussel, "Reconfigurable manufacturing systems", Ann. CIRP, vol. 48, no. 2, pp.1-14, 1999.

[2] R.G. Askin, and Y. Huang, "Employee Training and Assignment for Facility Reconfiguration", In: Proceedings of the sixth IERC, Miami, pp. 426-431, 1997.

[3] J. Bokhorst, and J. Slomp, "Long-Term Allocation of Operators to Machines in Manufacturing Cells", In: Proceedings of the Group Technology/Cellular Manufacturing World Symposium, San Juan and Puerto Rico, pp. 153-158, 2000.
[4] B.A. Norman, W. Tharmmaphornphilas, K. L. Needy, B. Bidanda, R.C. Warner, "Worker assignment in cellular manufacturing considering technical and human skills ", Int. J. Prod. Res., vol. 40, no. 6, pp. 1479-1492, 2002.

[5] J. Slompa, B.V. Chowdary, N.C. Sureshc, "Design of virtual manufacturing cells: a mathematical programming approach", Robot. Comput. Integr. Manuf., vol. 21, no. 3, pp. 273-288, 2005.

[6] M. Solimanpur, I. Mahdavi, A. Aalaei, and M.M. Paydar, "MultiObjective Cell Formation and Production Planning in Dynamic Virtual Cellular Manufacturing Systems", Int. Conf. Business Information, vol. 7, pp. 6-8, 2009.

[7] I. Mahdavi, A. Aalaei, M.M. Paydar, M. Solimanpur, "Designing a mathematical model for dynamic cellular manufacturing systems considering production planning and worker assignment", Comput. Math. Appl., vol. 60, no. 4, pp. 1014-1025, 2010.

[8] J.J. Fan, and D.Z. Feng, "Design of cellular manufacturing system with quasi-dynamic dual resource using multi-objective GA", Int. J. Prod. Res., vol. 51, no. 14, pp. 4134-4154, 2013.

[9] R. G. Askin, and Y. Huang, "Forming Effective Worker Teams for Cellular Manufacturing", Int. J. Prod. Res., vol. 39, no. 11, pp. 2431-2451, 2001.

[10] K. Kolbe, Pure instinct, New York: Random House, 1999.

[11] L. Erin, R. Fitzpatricka, and G. Askin, "Forming effective worker teams with multi-functional skill requirements", Comput. Indust. Eng., vol. 48, pp. 593-608, 2005.

[12] E. Molleman, and J. Slomp, "Functional flexibility and team performance", Int. J. Prod. Res., vol. 37. no. 8, pp. 1837-1858, 1999.

(c) Fan et al.; Licensee Bentham Open.

This is an open access article licensed under the terms of the Creative Commons Attribution Non-Commercial License (http://creativecommons.org/licenses/by-nc/4.0/) which permits unrestricted, non-commercial use, distribution and reproduction in any medium, provided the work is properly cited. 